IRIDODIALYSIS

\title{
OPERATIVE TREATMENT OF FIVE CASES OF IRIDODIALYSIS*
}

\author{
BY \\ SÜREYYA GÖRDÜREN \\ AN KARA
}

TRAUMATIC iridodialysis is not uncommon. It disturbs the patient because of the cosmetic and functional defects, such as dazzling, decreased visual acuity, and unilateral diplopia. Hence early treatment is necessary.

Although operative treatment was first performed by Amedée (1866), and later by some other ophthalmologists, it did not attract attention and general interest till Golowin (1917).

Iridodialysis may be single and so small as to be hardly seen by the naked eye, or large and multiple. The minute dialysis is often covered by an arcus senilis or the upper lid, and is not visible. Those that are new and without any disfigurement in the pupil may be left and no operative treatment is necessary.

Cases of total dialysis do not require surgical treatment so long as they do not develop secondary glaucoma.

In the operative treatment of iridodialysis many procedures are put forward. They may be divided into two general groups:

1 - Operations which are based upon the incarceration of iris root between the lips of a keratome incision or impinging the iris root against the posterior surface of the cornea by means of 2 or 3 sutures (van Lint, Key, Jameson).

2 - Those which are based upon grasping and pulling the iris root between the lips of a keratome incision with an iris hook or forceps, and performing the operation without any suture (Golowin).

The following five cases have been treated with some modification of the Golowin operation.

After local anaesthesia a keratome incision is made just on the level of the iris root and parallel to its anterior surface. The knife is slowly withdrawn and the iris root allowed to come between the lips of the incision with the outflow of aqueous humour; then with two spatulae slight adjustments are made to keep the iris root evenly in the lips of the wound. Atropine solution of 1 per cent. is instilled, and both eyes are covered. Next day there was no dialysis. There was a slight groove in the pupil of the first case (Fig. 2), while in the second there was no difference between the operated and normal eyes (Fig. 4).

The day after operation we allowed the patients to sit up in bed, with their back reclining on the pillow, the third day allowed them

- Received for publication, October 15, 1947. 
to walk in the room, and the seventh day opened the eye and let them resume their work.

In the third, fourth and fifth cases the dialyses were larger and very old (3-12 years). The iris root which we tried to insert between the the lips of the wound by means of a spatula easily escaped. We therefore inserted the iris hook between the iris and the lens and caught it in the central part of dialysis just close to the iris root; brought it between the lips and, moving the hook laterally, let the hook free. Then using the spatula, the lateral parts of the iris root were stroked between the lips of the wound; atropine was instilled, and both eyes were closed.

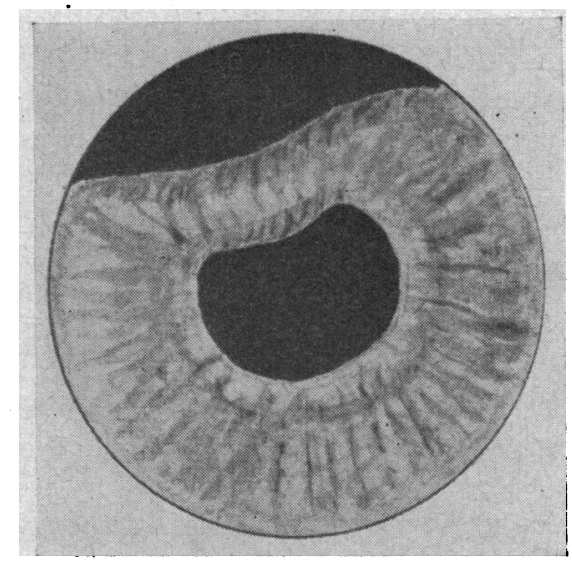

Fig. J.

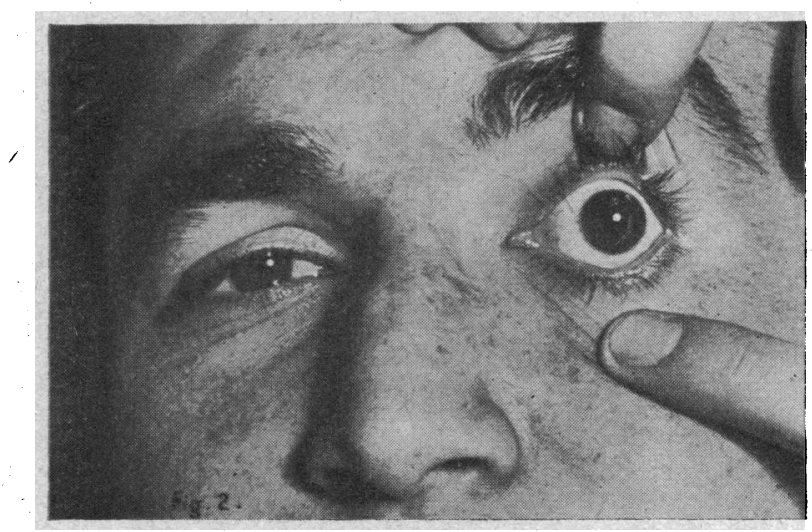

FIG. 2. 


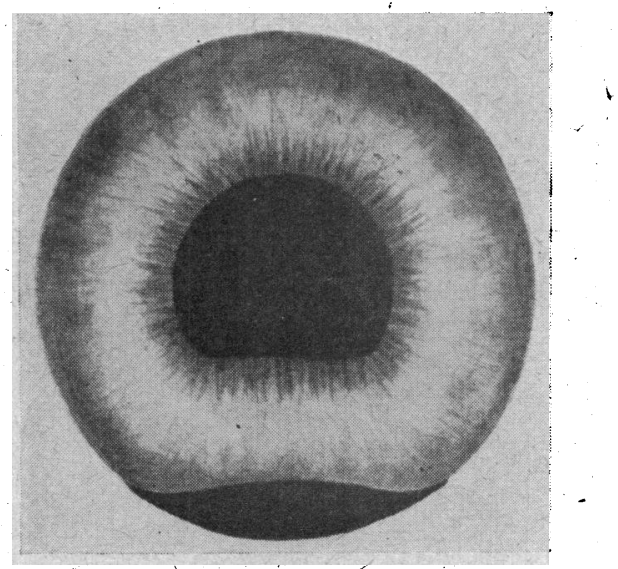

FIG. 3.

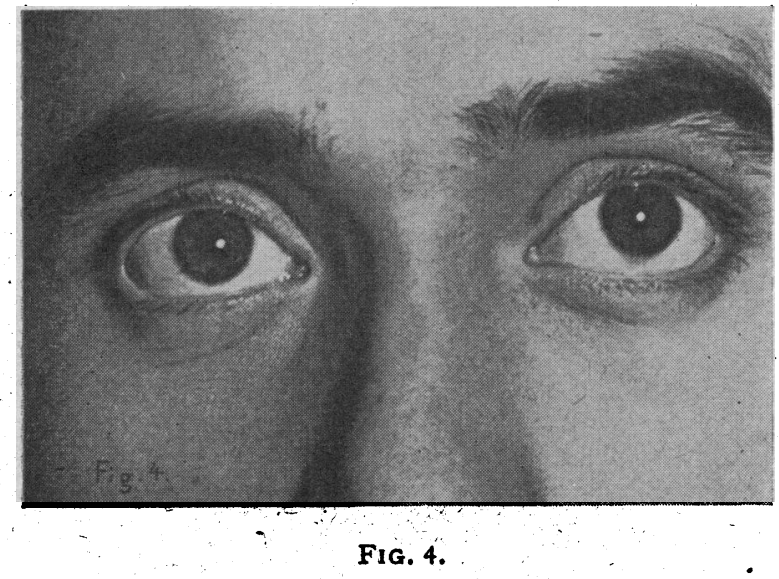

Fig. 4 .

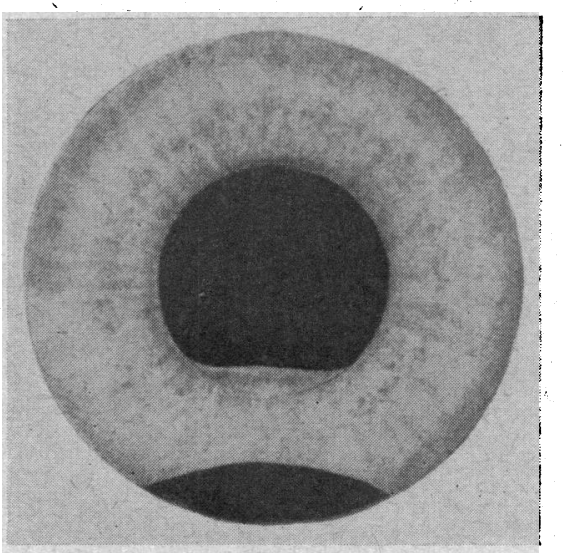


In cases where the first procedure is not possible, the second procedure consisting of pulling the iris root with an instrument, is applied. There is the danger of damaging the lens. For this. reason I prefer to catch the iris from behind with the tip of the

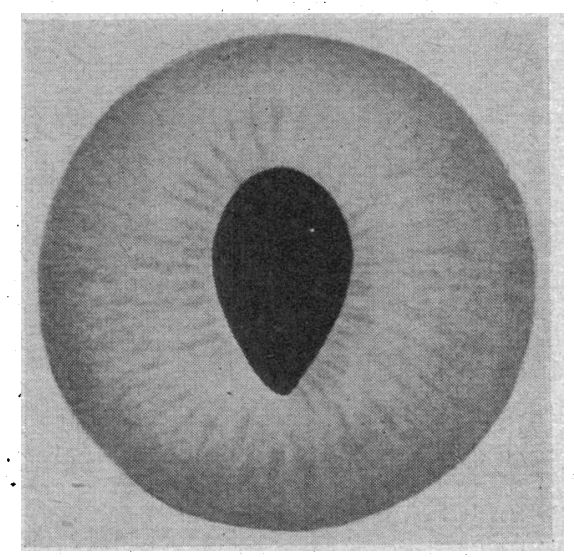

FIG. 6

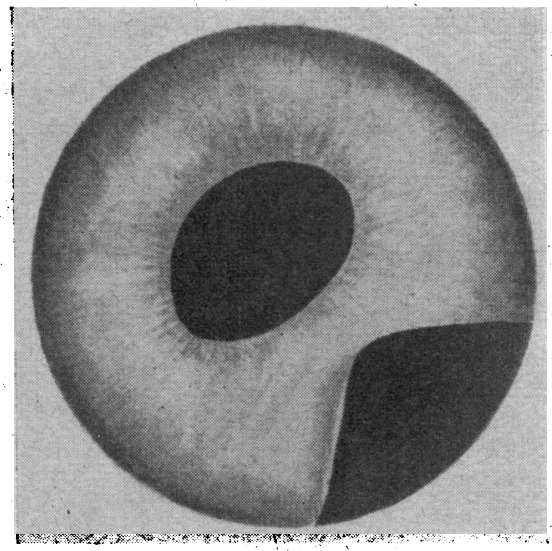

FIG. 7.

hook upwards. To use iris forceps sèms more dangerous for the lens.

Although iridodialysis was corrected in the last three cases, it left a deep grove in the pupil margin (Figs. 6, 8, 10).

We believe that the first method is preferable to the others. Here 
there is no danger of damaging so fine a tissue as the iris by grasping it with iris forceps or hook. This method is also safe for the lens.

In this method the iris root having been incarcerated evenly and in a smaller exent the pupil has a more regular shape compared,

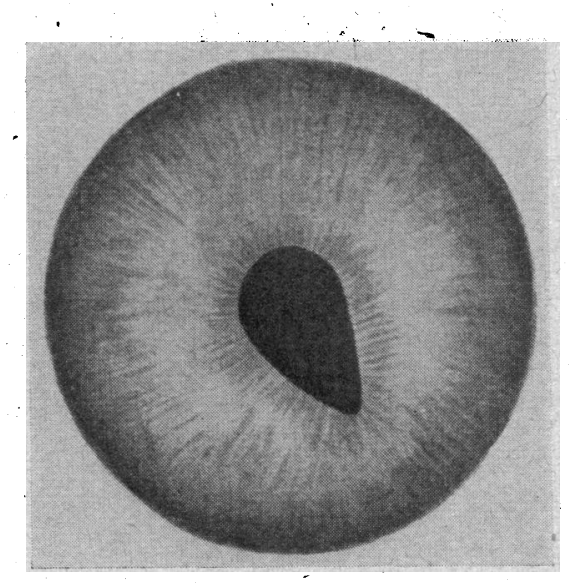

FIG. 8.

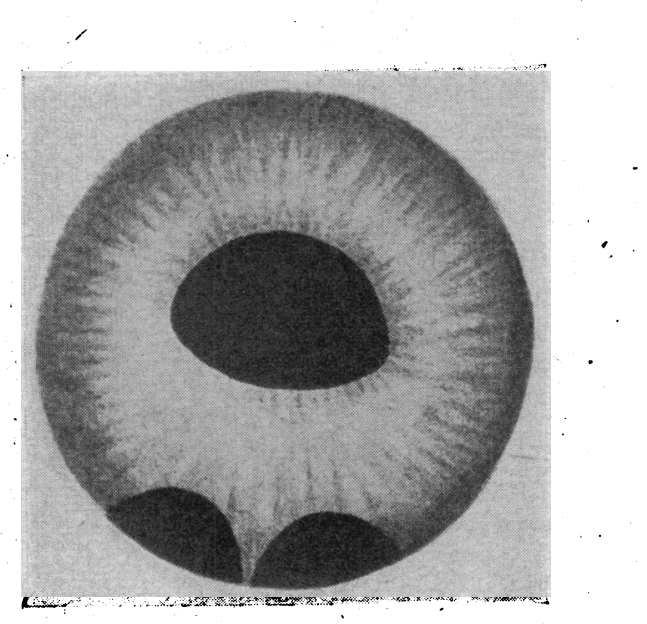

Fig. 9.

with the cases where a sharp groove is caused by traction with forceps or hook.

Wheeler (1934) recommends avoiding an operation on iridodialysis, unless there is a good reason for it, and even then adopting a simple method. 


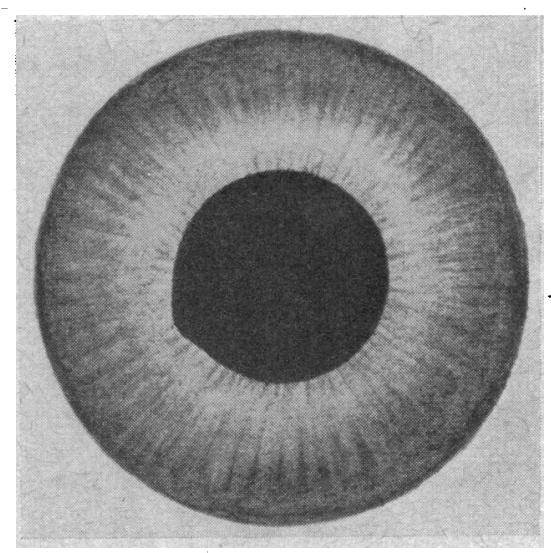

FIG. 10.

Encouraged by the simplicity of the operative procedure, and by good cosmetic and functional results, we believe that the operative treatment of iridodialysis is necessary.

\section{Case reports}

(1) O.S., a young man aged 21 years, complained of dazzling and poor vision of the left eye. Three months ago a stone struck his left eye.

There was an iridodialysis in the left eye about at 11 o'clock meridian (Fig; 1). There were traumatic lens opacities, and partly atrophic pigmented patches in macular region. He could count fingers at $1 / 2$ metres distance. After operation dialysis was corrected (Fig. 2), he could count fingers at 1.5 M., and there was no dazzling.

(2) S.U., a young man, aged 22 years, complained of monocular diplopia and a poor vision in the left eye. Three months ago a stone had struck his left eye. There was an iridodialysis at 6 o'clock meridian (Fig. 3). There were traumatic lens opacities and pigmented patches in the macular region. He could count fingers at $1 / 2$ metres distance. After operation iridodialysis was corrected (Fig. 4), vision 10/200, and no diplopia.

(3) H.K., a young man, aged 22 years, complained of dazzling in the right eye. Ten years ago a piece of iron had struck his right eye. There was an iridodialysis at 6 o'clock meridian (Fig. 5), vision 20/25. After operation dialysis was corrected (Fig. 6), vision $20 / 20$, and no dazzling.

(4) S. D., a young man, aged 22 years, complained of dazzling 
in the left eye. Three years ago the butt of his fowling-piece hit him on his left eye.

There was an iridodialysis at 4.30 o'clock meridian (Fig. 7), vision 20/25. After operation dialysis was corrected (Fig. 8), vision $20 / 20$, and no dazzling.

(5) M. K., a young man, aged 20 years, complained of dazzling and poor vision in the right eye. Twelve years ago a piece of stone had struck his right eye. There were two iridodialyses, separated from one another by a narrow bridge, one at 5.30 and the other at 6.30 o'clock meridian (Fig. 9). There were traumatic lens opacities, vision 20/100. Three operations were performed. Now no dialysis (Fig. 10), and no dazzling. Visual acuity same as before.

\title{
REPERENCES
}

Blaskovics (1938).-Eingriffe am Auge, p. 327.

GILBERT, W. (1930).-Kurzes Handbuch der Ophthal., V. Band, p. 101.

SPAETH, EDMOND (1944).- - Principles and Practice of Ophthalmic Surgery, p. 584

THIEL, RUdOLF (1943).-Ophthalmologische Operationslehre, p. 346.

\section{SIX CASES OF SCINTILLATIO ALBESCENS*}

\author{
BY \\ SÜREYYA GöRDÜREN
}

ANKARA

Scintillatio albescens is one of the endogenous deposits in the vitreous. The latter, as a whole, is not frequent. Dor found 32 cases in 82,732 patients, and Westphahl 40 cases in 65,000 .

They were known even in pre-ophthalmoscopic days, but until Benson (1894), little was known about the types of the disease. He divided them into two groups:

1. Asteroid hyalitis.

2. Synchisis scintillans.

The former type occurs in normal vitreous, and consists of white, spherical bodies; while the latter occurs in a fluid vitreous and appears as sparkling gold particles.

The cases to be described are typical examples of the first group.

1. R. G., a man, aged 58 years, complaining of weakness and weariness, was admitted to Gülhane Hospital. He was suffering from a mild diabetes for 16 years, and was leading his normal life with a mild diet.

His last blood serum examination revealed, when hungry, $248 \mathrm{mg}$. per cent. of glucose, this rose to $325 \mathrm{mg}$. when given $50 \mathrm{~g}$. of glucose,

- Received for publication, October 15, 1947. 